\title{
Potential Application of Mesenchymal Stem Cells and Their Secretory Factors for Musculoskeletal Disorders: A Brief Review
}

\author{
${ }^{1}$ Aditi Mahajan, ${ }^{2}$ Siddhartha Sharma, ${ }^{3}$ Shalmoli Bhattacharyya
}

\begin{abstract}
Musculoskeletal system accounts for the support, stability, and locomotion or movement of the human body. Musculoskeletal disorders (MSDs) include any injury, damage or disorder of muscles, bone, cartilage, tendons, ligaments, and joints in upper/ lower limbs or the back. Mesenchymal stem cells (MSCs) are being increasingly used for a variety of MSDs owing primarily to their excellent regenerative potential. The major mechanism through which MSCs participate in tissue repair is by the secretion of a broad repertoire of molecules which serve a myriad of biological functions. These molecules, collectively called as secretome, provide a way for cell free therapy by surpassing the limitations of cellular therapy and at the same time, provide equivalent benefits to the recipient. Cell free therapy utilizing only the secretome of MSCs has gained popularity in the past few years, and various preclinical studies have employed either the soluble factors, or vesicles, or complete secretome not only for disorders of musculoskeletal system but also of central nervous system, cardiac system, circulatory system, and autoimmunity. However, the exact mechanism of action of many of these molecules still remains to be discovered. Therefore, achieving an optimal outcome of tissue function restoration by designing a cell free therapeutic regimen using only secretome remains a major challenge. While acknowledging the potential of MSC secretome in other areas of regenerative medicine, this review will elucidate the regenerative potential of MSCs and their secretome in MSDs.
\end{abstract}

Keywords: Conditioned media, Mesenchymal stem cells, Muscle repair and regeneration, Musculoskeletal disorders, Secretome.

How to cite this article: Mahajan A, Sharma S, Bhattacharyya S. Potential Application of Mesenchymal Stem Cells and Their Secretory Factors for Musculoskeletal Disorders: A Brief Review. J Postgrad Med Edu Res 2018;52(2):73-82.

Source of support: Nil

Conflict of interest: None

${ }^{1} \mathrm{PhD}$ Scholar, ${ }^{2}$ Assistant Professor, ${ }^{3}$ Additional Professor and Head

${ }^{1,3}$ Department of Biophysics, Postgraduate Institute of Medical Education and Research, Chandigarh, India

${ }^{2}$ Department of Orthopedics, Postgraduate Institute of Medical Education and Research, Chandigarh, India

Corresponding Author: Shalmoli Bhattacharyya, Additional Professor and Head, Department of Biophysics, Postgraduate Institute of Medical Education and Research, Chandigarh, India Phone: +911722755251, e-mail: shalmoli2007@yahoo.co.in

\section{INTRODUCTION}

Musculoskeletal system accounts for more than half of the body mass and is responsible for not only the basic movements and locomotion but also for the protection of vital organs, mineral homeostasis, and hematopoiesis. Given the diverse functions of this system, it is not surprising that MSDs encompass a wide variety of conditions that range from trauma, degenerative disorders, metabolic disorders, neoplasia, arthritides, and developmental disorders, to name a few. Severe tissue loss and degeneration due to road accidents, excessive sports practice, and certain genetic abnormalities compromise the self-healing capacity of muscles and bones, thus limiting the structural and functional recovery of these tissues. In the everexpanding quest for newer therapies, biological therapies, especially those utilizing MSCs, have gained popularity, as these hold the promise of tissue regeneration. They are routinely employed in numerous studies involving disorders like bone, ${ }^{1,2}$ cartilage defects, ${ }^{3,4}$ neurodegeneration, ${ }^{5,6}$ renal failure, ${ }^{7,8}$ liver failure, ${ }^{9}$ diabetes ${ }_{,}^{10}$ ischemia, ${ }^{11}$ wound healing, ${ }^{12}$ and retinal damage. ${ }^{13}$ After the initial widespread enthusiasm, the potential clinical translation of stem cell therapy has been hindered by many pitfalls including necrosis of the cells at the injury site, teratoma formation, immune rejection, reduced quality due to in vitro expansions, and variable outcomes due to differences in the sources and donors. ${ }^{14}$ Previously, the reparative effects of MSCs were accredited to their ability for local engraftment and differentiation into cells of particular lineage. However, some studies have revealed that secretion of multitude of bioactive factors by MSCs, which play key roles in regulating diverse biologic processes, may account for their actual therapeutic benefits. Thus, it is now being proposed that the cardinal mode of action by which MSCs engage in tissue rejuvenation is via a paracrine activity by secretion of large repertoire of soluble molecules that can altogether reduce tissue or organ injury, mobilize the local stem cells to protect it from further degradation, and/or enhance its repair. ${ }^{15}$ The secretome of MSCs is thought to serve as multifarious biological functions, which include cell survival and proliferation, antiapoptosis, cell contractility, migration, angiogenesis, anti-inflammation, immune-modulation, 
cell differentiation, and homing of resident stem cells concomitantly contributing to the tissue refurbishment and restoration of the damaged tissue function. ${ }^{16}$ Thus, the design of cell free therapeutic regimen using only the secretory factors to achieve a favorable end-result for the repair and functional restoration is an interesting concept which is still nascent. This review aims to present a brief overview of MSCs and their secretory factors for management of various MSDs.

\section{Mesenchymal Stem Cell Therapy in MSDs}

The reparative attributes of MSCs have rendered them as attractive therapeutic vehicles to repair and restore tissue functions. The first study involving MSCs dates back to 1960s when they were first isolated and identified by Friedenstein and colleagues from bone marrow. This population of cells had the ability to indefinitely proliferate, self-renew, and trans-differentiate into cells of multiple origins, such as neuronal cells, osteoblasts, cardiomyocytes, chondrocytes, fibroblasts, myocytes, adipocytes, and hepatocytes. ${ }^{17}$ Later, MSCs from various other areas, such as dental tissue, synovial fluid, adipose tissue, placenta, umbilical cord, etc., have been utilized in preclinical and clinical studies to explore their efficacy in diverse areas of regenerative medicine. ${ }^{18}$ Stem cell therapy is widely being used in the treatment of MSDs. The basic aim of the therapeutic use of MSCs is to exploit the reparative and regenerative potential of these cells into replacing or restoring the functions of injured tissues or organs. The clinical application of MSCs requires them to be harvested with minimal invasion in abundant quantities, be safe and effectively transplanted into auto- or allogenic hosts, and be able to trans-differentiate into tissue-specific lineage upon administration. ${ }^{19}$ Mesenchymal stem cells have been employed in MSDs, particularly in bone and cartilage defects since more than a decade. In a study by Dahlin et al, ${ }^{20}$ the effects of bone marrow-derived stem cells (BMSCs) in combination with articular chondrocytes were evaluated in a rat model of osteochondral defects. For this, the cells were seeded on poly- $\varepsilon$ caprolactone scaffolds either in isolation or as coculture and then implanted in the defect created in the trochlear groove of the rat. The coculture resulted in the formation of hyaline cartilage as compared with MSCs alone group which formed fibrocartilage tissue. However, there was an equitable mineralized bone formation in both the groups. The results of this study evidenced the potential of coculture of MSCs + articular chondrocytes for the treatment of cartilage defects in vivo. Recently, Lee et $\mathrm{al}^{21}$ explored the efficacy of adipose tissue-derived stem cells (ADSCs) in repair of tendon injury in a rat model. For this, the cells were implanted along with fibrin glue at the site of Achilles tendon defects. There was an overall better biomechanical recovery in the group treated with ADSCs. Western blot analysis confirmed the greater expression of collagen type I and tenascin C proteins in the ADSCs treated group. Overall, the results suggested the potential role of ADSCs in the treatment of human tendinopathies. In another study, MSCs derived from bone marrow were used in a Duchenne muscular dystrophy (DMD) mice model. Administration of BMSCs improved DMD pathological conditions in addition to death-related symptoms, thus resulting in overall lifespan extension. The molecular analysis revealed that the expression of CXCL-12 and paired box protein-7 by MSCs contributed to the muscle regeneration. ${ }^{22}$ In another study, MSCs derived from human umbilical cord were used to treat intervertebral disk degeneration (IVD) in a rabbit model. The histological analysis showed significant improvement in terms of formation of extracellular matrix (ECM) proteins and glycosaminoglycan in the group treated with chondroprogenitor cells (CPCs) derived from MSCs. Also, specific markers, such as Sox9, aggrecan, collagen II, Foxf1, and KRT19 were highly expressed in the group treated with CPCs. ${ }^{23}$ In addition to these preclinical animal studies, MSCs have also been employed in numerous clinical studies looking at the repair and treatment of MSDs. In one study, a patient suffering with patella-chondral defect underwent arthroscopy for the removal of loose cartilage tissue. However, even after the 12 months period of follow-up, the patient failed to improve symptomatically, after which he was injected with autologous ADSCs. Within 3 months, the chondral defect was completely filled without any significant complications. ${ }^{24}$ In another study, 33 patients with IVD were treated with autologous BMSCs. Magnetic resonance imaging scans of 17 patients showed reduction in the size of disk bulge and overall improvement in the functional outcome. ${ }^{25}$ In another study, ADSCs were supplemented with demineralized bone matrix to fabricate a three-dimensional (3D) tissue construct, which was then implanted into 3 patients having bone tumor and other 3 patients suffering from bone pseudoarthrosis. The 3D bone-like structure fully repaired the bone defects, and no complications were observed in any of the case during the 4 years follow-up period. ${ }^{26}$ Table 1 enlists some of the studies employing MSCs for treatment of disorders associated with the musculoskeletal system.

\section{Pitfalls of Cell-based MSC Therapy}

The success of clinical translation of stem cell therapy is limited by multiple intrinsic as well as extrinsic risk factors. The intrinsic factors are associated with the characteristics of cells that are being transplanted, such as their origin, differentiation status, tumorigenic potential, proliferation capacity, lifespan, and long-term 
Table 1: Mesenchymal stem cells for various musculoskeletal disorders

\begin{tabular}{lll}
\hline$M S D$ & Source of MSCs & References \\
\hline Muscular dystrophy & Synovial membrane & 27 \\
& Muscles & 28 \\
& Adipose tissue & 29 \\
Amyotrophic lateral sclerosis & Bone marrow & 30 \\
& Bone marrow & 31 \\
& Adipose tissue & 32 \\
Meniscal tear & Neural tissue & 33 \\
& Synovial membrane & 34 \\
& Bone marrow & 35 \\
Bone defects & Adipose tissue & 36 \\
& Bone marrow & 37 \\
& Adipose tissue & 38 \\
& Dental tissue & 39 \\
Osteoarthritis & Umbilical cord & 40 \\
Tendon injuries & Adipose tissue & 4 \\
& Bone marrow & 41 \\
Intervertebral disk & Bone marrow & 42 \\
degeneration & Adipose tissue & 43 \\
\hline
\end{tabular}

viability, while the extrinsic factors are governed by human manipulations, such as cell procurement, culture conditions, contamination by adventitious agents, storage conditions, and transport conditions. Apart from these, the clinical characteristics of cellular therapy including the administration route, initiation of immune response, exposure duration, and underlying disease also affect the success of cellular therapy. ${ }^{46}$ These risk factors can result in rejection of cells, unwanted biological effects, neoplasm formation, disease transmission, reactivation of latent viruses, toxicity, and many unwanted physiological and anatomical consequences.

The major risk associated with the use of MSCs is teratoma formation. Because MSCs are multipotent in nature and secrete a variety of angiogenic factors, antiapoptosis factors, and growth factors, they provide conducive environment for the initiation and growth of tumor. Rubio et $\mathrm{al}^{47}$ showed that ADSC s be spontaneously transformed during prolonged in vitro culture. Another study in 2009 reported spontaneous malignant transformation of human BMSCs. This population of transformed MSCs displayed altered morphology, increased proliferation and growth in soft agar assays along with changes in phenotype. Tumorigenicity of the population was confirmed by transplantation into immunocompromised mice. ${ }^{48}$ The fact that stem cells can induce and promote tumor formation was also confirmed in some animal models. ${ }^{49,50}$ For instance, Prantl et $\mathrm{al}^{51}$ showed that ADSC s promoted tumor growth and progression when coinjected with prostate cancer cells. In another study, a male patient suffering from ataxia telangiectasia was treated with human fetal neural stem cells, after which he was diagnosed with brain tumor. The cytogenetic and molecular studies suggested that the tumor was of nonhost origin, indicating that it originated from the transplanted neural cells. ${ }^{52}$ The transplantation of MSCs is also limited by the immunocompatibility, risks of transmission of infections, and necrosis of the cells at the damaged site due to the presence of various proinflammatory cytokines. In addition, there are multiple reports, where the therapy utilizing MSCs have failed to produce the desired results and have rather aggravated the condition. In a case of chronic kidney injury induced in mice, the resident MSC-like cells moved to the site of injury and further aggravated the condition by causing vascular calcification. Genetic ablation of these cells significantly diminished the amount of calcification to a great extent, thus rescuing the vessel walls adjoining the injury site. ${ }^{53}$ In another instance, a combination therapy using MSCs and HSCs was used in patients with hematologic malignancy. It was observed that though this cotransplantation of cells was able to prevent graft-versus-host disease, it increased the frequency of relapse of malignancy. ${ }^{54}$

Thus, there is a need to look for alternatives that can overcome the risks of cellular therapy, but at the same time provide equivalent benefits to the recipients. In this regard, cell free MSC therapy has gained attention during the past few years which utilizes only the molecules secreted by MSCs. Till recently, much of the focus of clinical translation of MSC therapy relied on their ability to home to the damaged area and differentiate into cells of particular lineage, but the current insights into the molecular mechanisms of action of MSCs suggest that it is most likely exercised by the soluble factors and extracellular/microvesicles secreted by MSCs which have the anti-inflammatory and immunomodulatory properties. ${ }^{15}$ Thus, it is postulated that the secretome of MSCs regenerative potential similar to MSCs can circumvent the pitfalls associated with the use of cellular therapy.

\section{Regenerative Potential of Biological Molecules in MSC Secretome}

Although trophic factors and related signaling molecules secreted from MSCs are regarded as the central modus operandi for tissue reparative and regenerative effects of stem cells stands firm, a comprehensive knowledge on the exact molecular and signaling mechanisms of action of these molecules to bring about the complex tissue rejuvenation effects is still lacking. The secretome or the complete array of secreted factors of MSCs is reported to be encoded by $10 \%$ of the cellular genome, and include various molecules, such as proteins, proteases, ECM proteins, lipid mediators, growth factors, angiogenic factors, 
cell survival factors, cytokines, chemokines, hormones, microvesicles, exosomes, and some amount of nucleic acid, such as micro-ribonucleic acid (miRNA), messenger RNAs (mRNA), etc. ${ }^{55}$ There are two major pathways involved in the secretion of these molecules by stem cells-the first is the classical pathway that involves the translocation of molecules from endoplasmic reticulum to Golgi body and finally the excretion from the cell by endocytosis. The second mechanism involves the direct translocation and export of these molecules by membrane or protein-coated vesicles. ${ }^{56}$ The trophic factors secreted by stem cells play a myriad of biological functions, such as cellular survival, proliferation, contractility, migration, differentiation, antiapoptosis, vasculogenesis, attenuation of inflammation, and modulation of immune response, which eventually lead to the tissue remodeling and regeneration. Various mediators involved in such biological functions are depicted in Figure 1.

The earliest report of secretion of biologically active molecules by MSCs dates back to 1996 where Haynesworth et $\mathrm{al}^{57}$ reported the in vitro secretion of granulocyte colony-stimulating factor (G-CSF), stem cell factor, leukemia inhibitory factor (LIF), macrophage CSF (M-CSF), interleukin (IL)-6, and IL-11 by human BMSC. Since then, the list is expanding rapidly. The most common molecules secreted by MSCs from different sources include vascular endothelial growth factor (VEGF), hepatocyte growth factor (HGF), transforming growth factor (TGF)- $\beta$, insulin-like growth factor (IGF), fibroblast growth factor
(FGF), tumor necrosis factor (TNF)- $\alpha$, interferon (IFN)- $\gamma$, angiopoietin 1 (ANG1), ANG2, nerve growth factor, stromal cell-derived factor 1, prostaglandin E2 (PGE2), G-CSF, GM-CSF, M-CSF, LIF, BNP, IL-1, IL-6, IL-10, IL-11, Activin A, and SMAD proteins. ${ }^{15}$ These secreted factors are highly diluted and often present in nanogram scale, thus posing a great challenge in their characterization. Although there are a multitude of methods available to decipher the cellular secretome, the most widely used technology is one-dimensional sodium dodecyl sulfatepolyacrylamide gel electrophoresis followed by liquid chromatography tandem mass spectrometry. Other techniques include serial analysis of gene expression, deoxyribonucleic acid and protein microarrays, RNA sequencing, transcriptome analysis, mass spectrometry, and yeast secretion trap assay. ${ }^{58}$ The major signaling pathways that mediate the release of trophic factors by MSCs include Akt signaling for expression of VEGF, FGF2, HGF, IGF1 and TB4, JAK/STAT signaling for expression of VEGF and TGF- $\beta 1$, p38 mitogen-activated protein kinase (MAPK) signaling in the expression of HGF, IGF-1, IL-6, IL-8, and CXCL-1 and TNF receptor-mediated signaling in the expression of TNF, IGF-1, IL-6, and VEGF. ${ }^{15}$

\section{Mechanism of Regenerative Activity of MSC Secretome}

The principal mode of action of MSCs is their paracrine activity, which involves the secretion of various molecules

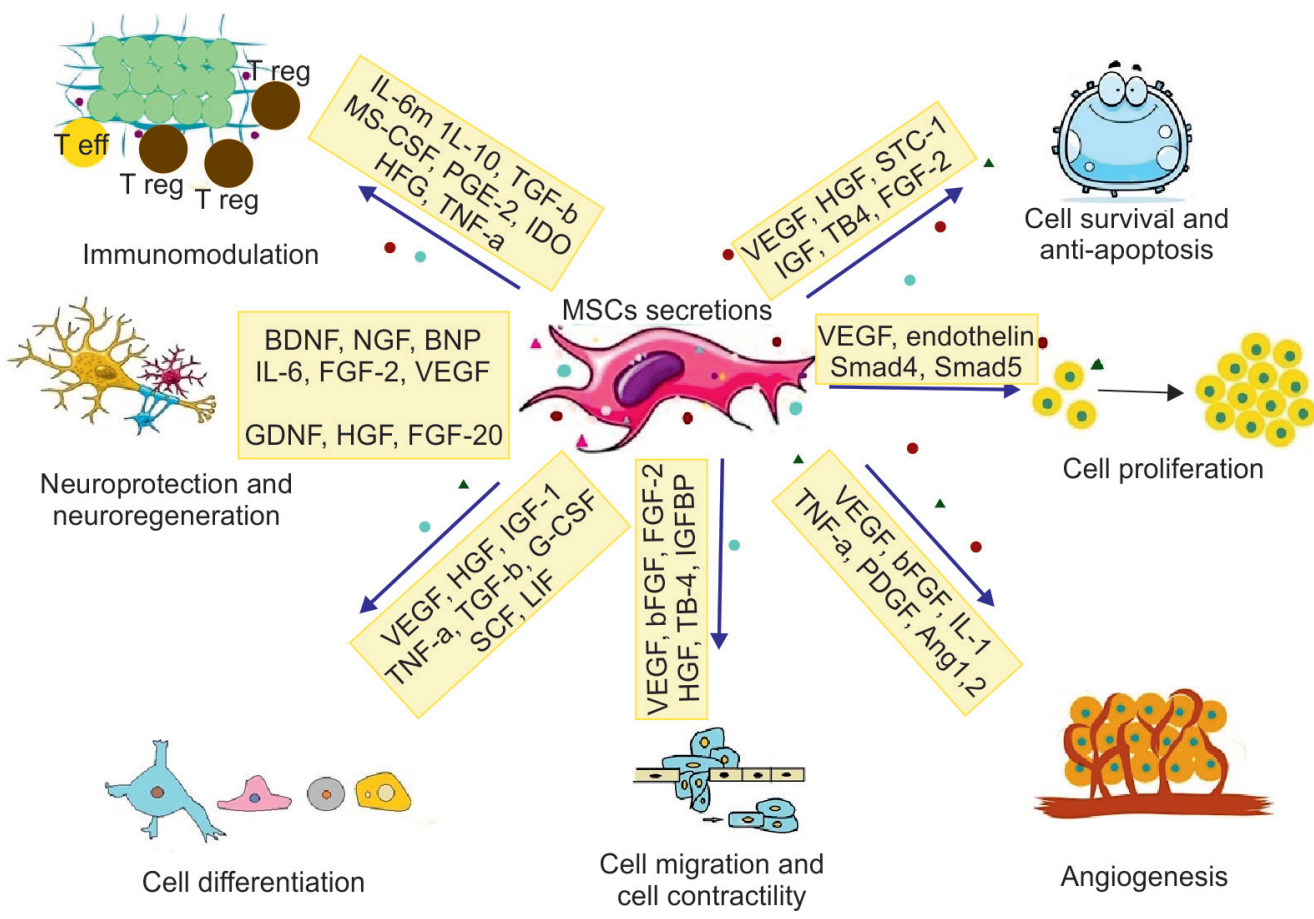

Fig. 1: Biological functions of MSCs secretions: Different trophic factors secreted by MSCs are involved in various functions including cell survival, antiapoptosis, cell proliferation, angiogenesis, cell migration and contractility, cell differentiation, neuroprotection and regeneration, tissue remodeling, antiinflammation, and immunomodulation 
having tissue protective effects. The secretome of MSCs plays a pivot role in attenuating tissue damage by two mechanisms: By neutralizing the proinflammatory molecules present at the site of damage and secondly by immunosuppressive effect. The latter is mediated by TGF- $\beta 1$, HGF, nitric oxide (NO), IL-10, PGE2, and indoleamine-pyrrole 2,3-dioxygenase. ${ }^{59}$ Another feature of paracrine therapy is microvesicle/exosome secretion which provides a crucial aspect in tissue repair and remodeling. These act as paracrine effectors as they can transport not only soluble molecules but also genetic material locally or by biological fluids, thus establishing a direct proteomic and genomic interactions between the secreting and responding cell. Thus, it is plausible to postulate that stem cells exercise their tissue protective effects at least partially by secreting such vesicles that can deliver certain molecules or transcription factors that can regulate the expression of target genes, such as those promoting cell survival, vasculogenesis, and tissue repair activation. ${ }^{60}$ In addition to this, the secretory factors also provide the necessary cues to directly differentiate the MSCs into specific lineages. In a recent study, it was reported that a pre-neuroblastic cell line showed increased neurite extensions, neurofilaments, and neural gene expression profile when treated with stem cells-conditioned medium. ${ }^{61}$ The first concrete evidence of therapeutic benefits and consequent clinical usage of MSCs secretome dates back to 2007, where Parekkadan et $\mathrm{al}^{62}$ reported that the paracrine mediators derived from BMSCs had an ability to reverse fulminant hepatic failure in mice. The angiogenic capability of MSCs secretions was evaluated in a myocardial infarction pig model, wherein the MSCs-conditioned medium reduced the myocardial infarct size and preserved systolic and diastolic performance, thus eventually leading to the preservation of cardiac function. ${ }^{63}$ The neuroprotective effects of BMSCs secretome were evaluated in a preclinical rat model of traumatic brain injury. It was observed that the rats treated with the secretome group displayed increased neurogenesis and performed better in motor and cognitive function tests. ${ }^{64}$ In another study, MSC-conditioned medium was used to assess the physiological recovery of a rat Parkinson's model. It was observed that the secretome increased the dopaminergic neurons and neural terminals in substantia nigra and striatum respectively, resulting in an overall recovery in motor performance outcomes. Proteomic evaluation of the secretome unveiled the existence of key neuroregulatory molecules, such as cystatin C, glia-derived nexin, galectin 1, brain-derived neurotrophic factor, IL-6, VEGF, pigment epitheliumderived factor, and glial cell line-derived neurotrophic factor. ${ }^{65}$ Recently, it was also reported that MSCs-derived microvesicles could possibly reverse the kidney failure in a nephrectomy mice model. Levels of serum creatinine, uric acid, and proteinuria were reduced significantly in the treatment group. In comparison to the control group, the remnant kidneys displayed lesser fibrosis, interstitial lymphocyte infiltration, and reduced tubular atrophy. ${ }^{66}$ In another instance, the effects of ADSCs and their secretory molecules were evaluated in a preclinical streptozotocininduced diabetes mellitus mice model. In both the cases, mechanical, thermal allodynia, and hyperalgesia were reversed, with a rapid and more persistent effect. Both the treatment strategies were able to re-establish the Th1/Th2 cytokine balance that was shifted to Th1 during diabetes. ${ }^{67}$ Recently, it was also reported that secretome derived from periodontal ligament stem cells from patients with multiple sclerosis was used in treatment of experimental autoimmune encephalomyelitis mice model. The holographic polymer dispersed liquid crystal-conditioned medium blocked NALP3 inflammasome activation and reduced the expression of proinflammatory TLR-4 and nuclear factor (NF)- $\beta .^{68}$

\section{MSC Secretome in MSDs}

The MSCs and their trophic factors have been reported to play therapeutic role in various MSDs, ranging from rheumatic diseases, osteoporosis, muscle repair to bone defects, and spinal cord injuries. ${ }^{69} \mathrm{Kim}$ et $\mathrm{al}^{70}$ evaluated the effect of secretory molecules rat model of muscle atrophy using conditioned medium derived from human umbilical cord MSCs (UC-CM). The group treated with UC-CM displayed increased muscle mass and muscle fibers and decreased lactate accumulation. In addition, the expression of desmin and skeletal muscle actin was found to be elevated, while there was a reduced expression of atrophy-related ubiquitin E3 ligase, muscle ring finger 1 , and muscle atrophy F box in the treatment group. They showed that secretome exerted its effect by the activation of P13K/Akt pathway, resulting in recovery of muscle status and function. In another study, secretome from amniotic fluid derived stem cells was assessed for its regenerative effects in a tibial anterior muscle injury model, and the results of the study suggested that extracellular vesicles present in the secretome were capable of promoting tissue repair and recovery by targeting proapoptotic and senescence-related mRNA. ${ }^{71}$ In another study, BMSC-derived secretome was administered both locally and systemically, to observe the effects on muscular degenerative changes and shoulder function on massive rotator cuff tears in a rat model. It was observed that even a single local injection of secretome reduced muscle fatty degeneration significantly and increased muscle mass, thus decreasing the atrophy of rotator cuff muscles. ${ }^{72}$ Nakamura et $\mathrm{al}^{73}$ investigated the role of MSCs exosomes 
in skeletal muscle regeneration. In vitro studies indicated that the exosomes promoted myogenesis and angiogenesis. In the animal model of muscle injury, exosomes were able to regenerate muscle which occurred partially as a result of delivery of miRNAs, such as miR-494. In another study, secretome from CD34+ stem cells caused significant attenuation of neurological deficits, number of apoptotic cells, extent of inflammation, oxidative stress, and astrogliosis in a rat preclinical model of spinal cord injury. ${ }^{74}$ Wang et $\mathrm{al}^{75}$ demonstrated that exosomes derived from MSCs exerted a beneficial therapeutic effect on osteoarthritis by maintaining a balance between the synthesis and degradation of chondrocyte ECM. Exosomes were tested in both in vitro and in vivo model simulating osteoarthritis and they were found to increase the collagen type II synthesis and decrease the expression of ADAMTS5. In another study involving osteoarthritis, conditioned medium from ADSCs downregulated the senescence markers, including senescence associated $\beta$-galactosidase activity and resulted in the accumulation of $\gamma \mathrm{Y} 2 \mathrm{AX}$ foci and morphological changes with enhanced formation of actin stress fibers. In vitro treatment of stress-induced senescencing chondrocytes with conditioned medium decreased oxidative stress, p53 acetylation, and stimulated the activation of MAPKs, caveolin 1, and p21. The results of this study established that MSCs secretome can counter the stress-induced premature senescence of osteoarthritis chondrocytes, and thus have the potential in treatment of degenerating joint diseases. ${ }^{76}$ The multifaceted beneficial effect of secretions of MSCs alone was also evaluated in an in vivo preclinical rheumatoid arthritis mouse model. In this case, treatment with the secretome obtained from human deciduous dental pulp stem cells induced antiinflammatory M2 macrophages and abrogated osteoclastogenesis by decreasing RANKL expression in arthritic joints. ${ }^{77}$ In another study by Platas et al, ${ }^{78}$ conditioned medium from ADSCs enhanced type II collagen expression and decreased matrix metalloproteinase (MMP) activity in osteoarthritic chondrocytes. Further, the secretome inhibited NF- $\beta$ activation and thus, reduced the stimulating effects of IL-1 $\beta$ in the producing proinflammatory cytokines, such as TNF- $\alpha$, IL-6, prostaglandins, and NO. Antiapoptotic effects due to paracrine mechanism of bone marrow-derived MSCs were evaluated in IVD in vitro. Both the MSCs and inflamed nucleus pulposus (NP) cells were cultured together, resulting in the transfer of stem cells mitochondria by tunneling nanotubes. This mitochondrial transfer was responsible for decreased expression of inflammation associated genes, such as ADAM-TS4, ADAM-TS5, caspase 3, and MMP-13. ${ }^{79}$ The protective effects of exosomes were also demonstrated in IVD disease. The results indicated that exosomes delivered miR-21 to the apoptotic NP cells, and targeted phosphatase and tensin homolog (PTEN) through P13-K-Akt pathway, thus alleviating TNF- $\alpha$-induced apoptosis in these cells. ${ }^{80}$ In another study, the protective effects of exosomes were tested in vitro to ameliorate the pyroptosis induced by doxorubicin in rat muscle cells. The exosomes were able to inhibit pyroptosis and decrease the expression of caspase $1, \mathrm{IL}-1 \beta$, and IL-18. ${ }^{81}$ The secretome is thought to mediate its effect in case of skeletal disorders, particularly bone defects, due to secretion of molecules like decorin, osteoprotegerin, Dkk-3, receptor activator of nuclear B (RANK) CCL2, IL3, IL-6, IL-7, MMP-7, and MMP-10. The MSC conditioned medium was also used in bisphosphonate-related jaw osteonecrotic rat model. In this case, MSC-CM rescued rat MSCs and osteoclasts and also upregulated the expression of osteogenic and neovascularization-related genes. ${ }^{82}$ In the first ever patient study utilizing conditioned medium derived from MSCs for bone repair, 8 patients needing extraneous bone augmentation were treated with beta tricalcium phosphate or atelocollagen sponge soaked in MSC-CM and followed up for 6 months. There were no local or systemic complications during the entire period of the study. Radiographic and histological examination revealed accelerated bone formation in all the cases. ${ }^{83}$ In another preclinical study, the secretions of ADSCs were used in ovariectomized mice. It was reported that the conditioned media was able to stimulate the proliferation and differentiation of osteoblasts by activating SMAD/extracellular signal regulated kinase (ERK) / c-jun- $\mathrm{NH}_{2}$-terminal kinase (JNK) pathway, and of osteoclasts by activating ERK/JNK/p38 pathway. The results of this study indicated that the paracrine mediators secreted by ADSC s stimulate bone regeneration and thus prove to be effective in the treatment of osteoporosis. ${ }^{84}$ In case of rat calvarial bone defects, the group receiving the secretome of bone marrow-derived MSCs displayed greater area of bone regeneration compared with the one receiving only MSCs. ${ }^{85}$ The stem cell secretome is also reported to accelerate distraction osteogenesis (DO) in a mouse H-DO model. The local administration of secretome resulted in the inhibition of inflammatory response and promoted vasculogenesis and differentiation and proliferation of osteoblasts, thus accelerating the bone augmentation in the mouse H-DO model. ${ }^{86}$ Proteomic analysis of the MSCs secretome has shown the presence of various molecules known to be involved in muscle and bone regeneration, thus contributing to its musculoskeletal protective effects. For example, MSCs secrete MMP-10, which regulates the CXCL-12 stimulation of resident stem cells migration toward defect site, thus influencing adult muscle repair. The IGF-1 is also secreted by muscles where it is involved in the coupling of both muscle and bone anabolism. The FGF-2 is a well-known osteogenic factor that contributes significantly in alleviating the 
Table 2: Mesenchymal stem cells' secretory factors in regeneration of musculoskeletal system

\begin{tabular}{ll}
\hline Trophic factors secreted by MSCs & Role in musculoskeletal system \\
\hline IGF1, FGF2, GDF8, IL7, IL15 & $\begin{array}{l}\text { Promote bone formation, stimulate muscle repair and regeneration: beneficial during } \\
\text { fracture healing and muscular dystrophy } \\
\text { Myocytes proliferation and differentiation, regeneration of myotubes, muscles repair: } \\
\text { play role in skeletal muscle repair and muscular atrophies }\end{array}$ \\
Myogenic precursor cell proliferation, differentiation of myotubes: beneficial in muscular \\
atrophies
\end{tabular}

muscles-related traumatic injuries. Growth and differentiation factor (GDF)-8 or myostatin is also produced by MSCs, which naturally enhances the muscles and bone repair. In addition, the cytokines released by MSCs, such as IL-6, IL-7, and IL-15, also called as myokines, promote muscle repair and regeneration. ${ }^{15,87}$ Table 2 enlists various molecules secreted by MSCs that play crucial roles during diseases of the musculoskeletal system. Owing to their beneficial effects in repair and regeneration of tissues/ organs of musculoskeletal system, various studies have employed the conditioned media or secretome of MSCs for treatment of MSDs.

It is clear that the aforementioned studies have involved the administration of MSC-conditioned media, which provided the comparative clinical benefit as that of MSCs alone, and at the same time, bypassed the risks associated with the use of cellular therapy.

\section{CONCLUSION}

MSCs-based treatment strategies have been employed in various animal studies and clinical trials for treatment of bone and cartilage defects, muscles repair and regeneration, and in many tendon and ligament injuries. However, side effects of cell-based therapy limit their widespread use. Cell free therapy in the form of secretome of MSCs may serve as a ready-to-go biological therapeutic agent, and may provide significant advantage over cellular therapy. Ongoing research is focusing on understanding of exact mechanisms, potential pitfalls and adverse effects of the MSC secretome, and clinical applications of such therapies may soon see light of the day.

\section{REFERENCES}

1. Arinzeh TL,PeterSJ,ArchambaultMP, VanDen BosC, GordonS, Kraus K, Smith A, Kadiyala S. Allogeneic mesenchymal stem cells regenerate bone in a critical-sized canine segmental defect. J Bone Joint Surg Am 2003 Oct;85-A(10):1927-1935.

2. Kitoh H, Kitakoji T, Tsuchiya H, Mitsuyama $H$, Nakamura $H$, Katoh M, Ishiguro N. Transplantation of marrow-derived mesenchymal stem cells and platelet-rich plasma during distraction osteogenesis-a preliminary result of three cases. Bone 2004 Oct;35(4):892-898.

3. Im GI, Kim DY, Shin JH, Hyun CW, Cho WH. Repair of cartilage defect in the rabbit with cultured mesenchymal stem cells from bone marrow. J Bone Joint Surg Br 2001 Mar;83(2): 289-294.

4. Jo CH, Lee YG, Shin WH, Kim H, Chai JW, Jeong EC, Kim JE, Shim H, Shin JS, Shin IS, et al. Intra-articular injection of mesenchymal stem cells for the treatment of osteoarthritis of the knee: a proof-of-concept clinical trial. Stem Cells 2014 May;32(5):1254-1266.

5. Jones J, Estirado A, Redondo C, Pacheco-Torres J, SirerolPiquer M-S, Garcia-Verdugo JM, Martinez S. Mesenchymal stem cells improve motor functions and decrease neurodegeneration in ataxic mice. Mol Ther 2015 Jan;23(1):130-138.

6. Bae JS, Han HS, Youn DH, Carter JE, Modo M, Schuchman EH, Jin HK. Bone marrow-derived mesenchymal stem cells promote neuronal networks with functional synaptic transmission after transplantation into mice with neurodegeneration. Stem Cells 2007 May;25(5):1307-1316.

7. Tögel $\mathrm{F}, \mathrm{Hu} Z$, Weiss $\mathrm{K}$, Isaac J, Lange C, Westenfelder C. Administered mesenchymal stem cells protect against ischemic acute renal failure through differentiation-independent mechanisms. Am J Physiol Renal Physiol 2005 Jul;289(1): F31-F42.

8. Villanueva S, Carreño JE, Salazar L, Vergara C, Strodthoff R, Fajre F, Céspedes C, Sáez PJ, Irarrázabal C, Bartolucci J, et al. Human mesenchymal stem cells derived from adipose tissue reduce functional and tissue damage in a rat model of chronic renal failure. Clin Sci (Lond) 2013 Aug;125(4):199-210.

9. Sato Y, Araki H, Kato J, Nakamura K, Kawano Y, Kobune M, Sato T, Miyanishi K, Takayama T, Takahashi M, et al. Human mesenchymal stem cells xenografted directly to rat liver are differentiated into human hepatocytes without fusion. Blood 2005 Jul;106(2):756-763.

10. Chao KC, Chao KF, Fu YS, Liu SH. Islet-like clusters derived from mesenchymal stem cells in Wharton's Jelly of the human 
umbilical cord for transplantation to control type 1 diabetes. PloS One 2008 Jan;3(1):e1451.

11. Heldman AW, DiFede DL, Fishman JE, Zambrano JP, Trachtenberg BH, Karantalis V, Mushtaq M, Williams AR, Suncion VY, McNiece IK, et al. Transendocardial mesenchymal stem cells and mononuclear bone marrow cells for ischemic cardiomyopathy: the TAC-HFT randomized trial. JAMA 2014 Jan;311(1):62-73.

12. Rodriguez-Menocal L, Shareef S, Salgado M, Shabbir A, Van Badiavas E. Role of whole bone marrow, whole bone marrow cultured cells, and mesenchymal stem cells in chronic wound healing. Stem Cell Res Ther 2015 Mar;6(1):24.

13. Mathew B, Poston JN, Dreixler JC, Torres L, Lopez J, Zelkha R, Balyasnikova I, Lesniak MS, Roth S. Bone-marrow mesenchymal stem-cell administration significantly improves outcome after retinal ischemia in rats. Graefes Arch Clin Exp Ophthalmol 2017 Aug;255(8):1581-1592.

14. Raik S, Kumar A, Bhattacharyya S. Insights into cell free therapeutic approach-role of Stem cell "soup-ernatant". Biotechnol Appl Biochem 2017 Mar. Epub ahead of print.

15. Xiao Y, Li X, Hao H, Cui Y, Chen M, Liu L, Liu Z. Secretome of mesenchymal stem cells. In: Zhao RC, editor. Essentials of mesenchymal stem cell biology and its clinical translation. Columbus (OH): Springer; 2013. pp. 33-46.

16. Konala VB, Mamidi MK, Bhonde R, Das AK, Pochampally R, $\mathrm{Pal} \mathrm{R}$. The current landscape of the mesenchymal stromal cell secretome: a new paradigm for cell-free regeneration. Cytotherapy 2016 Jan;18(1):13-24.

17. Bianco P, Robey PG, Simmons PJ. Mesenchymal stem cells: revisiting history, concepts, and assays. Cell Stem Cell 2008 Apr;2(4):313-319.

18. Kern S, Eichler H, Stoeve J, Klüter H, Bieback K. Comparative analysis of mesenchymal stem cells from bone marrow, umbilical cord blood, or adipose tissue. Stem Cells 2006 May;24(5):1294-1301.

19. Guan X, Furth ME, Childers MK. Stem cell use in musculoskeletal disorders. PM R 2011 Jun;3(6 Suppl 1):S95-S99.

20. Dahlin RL, Kinard LA, Lam J, Needham CJ, Lu S, Kasper FK, Mikos AG. Articular chondrocytes and mesenchymal stem cells seeded on biodegradable scaffolds for the repair of cartilage in a rat osteochondral defect model. Biomaterials 2014 Aug;35(26):7460-7469.

21. Lee SY, Kwon B, Lee K, Son YH, Chung SG. Therapeutic mechanisms of human adipose-derived mesenchymal stem cells in a rat tendon injury model. Am J Sports Med 2017 May;45(6):1429-1439.

22. Maeda Y, Yonemochi Y, Nakajyo Y, Hidaka H, Ikeda T, Ando Y. CXCL12 and osteopontin from bone marrow-derived mesenchymal stromal cells improve muscle regeneration. Sci Rep 2017 Jun;7(1):3305.

23. Beeravolu N, Brougham J, Khan I, McKee C, Perez-Cruet M, Chaudhry GR. Human umbilical cord derivatives regenerate intervertebral disc. J Tissue Eng Regen Med 2016 Sep. Epub ahead of print.

24. Freitag J, Li D, Wickham J, Shah K, Tenen A. Effect of autologous adipose-derived mesenchymal stem cell therapy in the treatment of a post-traumatic chondral defect of the knee. BMJ Case Rep 2017 Oct;2017:220852.

25. Centeno C,Markle J, Dodson E, Stemper I, Williams CJ,Hyzy M, Ichim T, Freeman M. Treatment of lumbar degenerative disc disease-associated radicular pain with culture-expanded autologous mesenchymal stem cells: a pilot study on safety and efficacy. J Transl Med 2017 Sep;15(1):197.
26. Dufrane D, Docquier PL, Delloye C, Poirel HA, André W, Aouassar N. Scaffold-free three-dimensional graft from autologous adipose-derived stem cells for large bone defect reconstruction: clinical proof of concept. Medicine (Baltimore) 2015 Dec;94(50):e2220.

27. De Bari C, Dell'Accio F, Vandenabeele F, Vermeesch JR, Raymackers JM, Luyten FP. Skeletal muscle repair by adult human mesenchymal stem cells from synovial membrane. J Cell Biol 2003 Mar;160(6):909-918.

28. Gussoni E, Soneoka Y, Strickland CD, Buzney EA, Khan MK, Flint AF, Kunkel LM, Mulligan RC. Dystrophin expression in the $\mathrm{mdx}$ mouse restored by stem cell transplantation. Nature 1999 Sep;401(6751):390-394.

29. Liu Y, Yan X, Sun Z, Chen B, Han Q, Li J, Zhao RC. Flk-1+ adipose-derived mesenchymal stem cells differentiate into skeletal muscle satellite cells and ameliorate muscular dystrophy in mdx mice. Stem Cells Dev 2007 Oct;16(5):695-706.

30. Bittner RE,Schöfer C, Weipoltshammer K, Ivanova S, Streubel B, Hauser E, Freilinger M, Höger H, Elbe-Bürger A, Wachtler F. Recruitment of bone-marrow-derived cells by skeletal and cardiac muscle in adult dystrophic mdx mice. Anat Embryol (Berl) 1999 May;199(5):391-396.

31. Vercelli A, Mereuta O, Garbossa D, Muraca G, Mareschi K, Rustichelli D, Ferrero I, Mazzini L, Madon E, Fagioli F. Human mesenchymal stem cell transplantation extends survival, improves motor performance and decreases neuroinflammation in mouse model of amyotrophic lateral sclerosis. Neurobiol Dis 2008 Sep;31(3):395-405.

32. Marconi S, Bonaconsa M, Scambi I, Squintani G, Rui W, Turano E, Ungaro D, D'Agostino S, Barbieri F, Angiari S, et al. Systemic treatment with adipose-derived mesenchymal stem cells ameliorates clinical and pathological features in the amyotrophic lateral sclerosis murine model. Neuroscience 2013 Sep;248:333-343.

33. Glass JD, Boulis NM, Johe K, Rutkove SB, Federici T, Polak M, Kelly C, Feldman EL. Lumbar intraspinal injection of neural stem cells in patients with amyotrophic lateral sclerosis: results of a phase I trial in 12 patients. Stem Cells 2012 Jun;30(6): 1144-1151.

34. Hatsushika D, Muneta T, Nakamura T, Horie M, Koga H, Nakagawa Y, Tsuji K, Hishikawa S, Kobayashi E, Sekiya I. Repetitive allogeneic intraarticular injections of synovial mesenchymal stem cells promote meniscus regeneration in a porcine massive meniscus defect model. Osteoarthritis Cartilage 2014 Jul;22(7):941-950.

35. Pabbruwe MB, Kafienah W, Tarlton JF, Mistry S, Fox DJ, Hollander AP. Repair of meniscal cartilage white zone tears using a stem cell/collagen-scaffold implant. Biomaterials 2010 Mar;31(9):2583-2591.

36. Ruiz-Ibán MÁ, Díaz-Heredia J, García-Gómez I, GonzalezLizán F, Elías-Martín E, Abraira V. The effect of the addition of adipose-derived mesenchymal stem cells to a meniscal repair in the avascular zone: an experimental study in rabbits. Arthroscopy 2011 Dec;27(12):1688-1696.

37. Bruder SP, Kraus KH, Goldberg VM, Kadiyala S. The effect of implants loaded with autologous mesenchymal stem cells on the healing of canine segmental bone defects. J Bone Joint Surg 1998 Jul;80(7):985-996.

38. Lendeckel S, Jödicke A, Christophis P, Heidinger K, Wolff J, Fraser JK, Hedrick MH, Berthold L, Howaldt HP. Autologous stem cells (adipose) and fibrin glue used to treat widespread traumatic calvarial defects: case report. J Craniomaxillofac Surg 2004 Dec;32(6):370-373. 
39. d'Aquino R, De Rosa A, Lanza V, Tirino V, Laino L, Graziano A, Desiderio V, Laino G, Papaccio G. Human mandible bone defect repair by the grafting of dental pulp stem/progenitor cells and collagen sponge biocomplexes. Eur Cell Mater 2009 Nov; $18: 75-83$.

40. Jang BJ, Byeon YE, Lim JH, Ryu HH, Kim WH, Koyama Y, Kikuchi M, Kang KS, Kweon OK. Implantation of canine umbilical cord blood-derived mesenchymal stem cells mixed with beta-tricalcium phosphate enhances osteogenesis in bone defect model dogs. J Vet Sci 2008 Dec;9(4):387-393.

41. Orozco L, Munar A, Soler R, Alberca M, Soler F, Huguet M, Sentís J, Sánchez A, García-Sancho J. Treatment of knee osteoarthritis with autologous mesenchymal stem cells: a pilot study. Transplantation 2013 Jun;95(12):1535-1541.

42. Awad HA, Boivin GP, Dressler MR, Smith FN, Young RG, Butler DL. Repair of patellar tendon injuries using a cellcollagen composite. J Orthop Res 2003 May;21(3):420-431.

43. Nixon AJ, Dahlgren LA, Haupt JL, Yeager AE, Ward DL. Effect of adipose-derived nucleated cell fractions on tendon repair in horses with collagenase-induced tendinitis. Am J Vet Res 2008 Jul;69(7):928-937.

44. Crevensten G,WalshAJ,Ananthakrishnan D,PageP,WahbaGM, Lotz JC, Berven S. Intervertebral disc cell therapy for regeneration: mesenchymal stem cell implantation in rat intervertebral discs. Ann Biomed Eng 2004 Mar;32(3):430-434.

45. AndersonDG,Markova D,AnHS,CheeA,Enomoto-Iwamoto M, Markov V, Saitta B, Shi P, Gupta C, Zhang Y. Human umbilical cord blood-derived mesenchymal stem cells in the cultured rabbit intervertebral disc: a novel cell source for disc repair. Am J Phys Med Rehabil 2013 May;92(5):420-429.

46. Herberts CA, Kwa MS, Hermsen HP. Risk factors in the development of stem cell therapy. J Transl Med 2011 Mar;9(1):29.

47. RubioD,Garcia-CastroJ,Martín MC, dela FuenteR,CigudosaJC, Lloyd AC, Bernad A. Spontaneous human adult stem cell transformation. Cancer Res 2005 Apr;65(8):3035-3039.

48. Røsland GV, Svendsen A, Torsvik A, Sobala E, McCormack E, ImmervollH, MysliwietzJ, TonnJC, Goldbrunner R, Lønning PE, et al. Long-term cultures of bone marrow-derived human mesenchymal stem cells frequently undergo spontaneous malignant transformation. Cancer Res 2009 Jul;69(13):5331-5339.

49. Shih CC, Forman SJ, Chu P, Slovak M. Human embryonic stem cells are prone to generate primitive, undifferentiated tumors in engrafted human fetal tissues in severe combined immunodeficient mice. Stem Cells Dev 2007 Dec;16(6):893-902.

50. Zhu W, Xu W, Jiang R, Qian H, Chen M, Hu J, Cao W, Han C, Chen $Y$. Mesenchymal stem cells derived from bone marrow favor tumor cell growth in vivo. Exp Mol Pathol 2006 Jun;80(3):267-274.

51. Prantl L, Muehlberg F, Navone NM, Song YH, Vykoukal J, Logothetis CJ, Alt EU. Adipose tissue-derived stem cells promote prostate tumor growth. Prostate 2010 Nov;70(15): 1709-1715.

52. Amariglio N, Hirshberg A, Scheithauer BW, Cohen $\mathrm{Y}$, Loewenthal R, Trakhtenbrot L, Paz N, Koren-Michowitz M, Waldman D, Leider-Trejo L, et al. Donor-derived brain tumor following neural stem cell transplantation in an ataxia telangiectasia patient. PLoS Med 2009 Feb;6(2):e1000029.

53. Kramann R, Goettsch C, Wongboonsin J, Iwata H, Schneider RK, Kuppe C, Kaesler N, Chang-Panesso M, Machado FG, Gratwohl S, et al. Adventitial MSC-like cells are progenitors of vascular smooth muscle cells and drive vascular calcification in chronic kidney disease. Cell Stem Cell 2016 Nov;19(5):628-642.
54. Ning $\mathrm{H}$, Yang F, Jiang M, Hu L, Feng K, Zhang J, Yu Z, Li B, $\mathrm{Xu}$ C, Li Y, et al. The correlation between cotransplantation of mesenchymal stem cells and higher recurrence rate in hematologic malignancy patients: outcome of a pilot clinical study. Leukemia 2008 Mar;22(3):593-599.

55. Tran C, Damaser MS. Stem cells as drug delivery methods: application of stem cell secretome for regeneration. Adv Drug Deliv Rev 2015 Mar;82-83:1-11.

56. Nickel W, Rabouille C. Mechanisms of regulated unconventional protein secretion. Nat Rev Mol Cell Biol 2009 Feb;10(2):148-155.

57. Haynesworth SE, Baber MA, Caplan AI. Cytokine expression by human marrow-derived mesenchymal progenitor cells in vitro: effects of dexamethasone and IL-1 $\alpha$. J Cell Physiol 1996 Mar;166(3):585-592.

58. Mukherjee P, Mani S. Methodologies to decipher the cell secretome. Biochim Biophys Acta 2013 Nov;1834(11):2226-2232.

59. Gao F, Chiu S, Motan D, Zhang Z, Chen L, Ji H, Tse HF, Fu QL, Lian Q. Mesenchymal stem cells and immunomodulation: current status and future prospects. Cell Death Dis 2016 Jan;7(1):e2062.

60. Bollini S, Gentili C, Tasso R, Cancedda R. The regenerative role of the fetal and adult stem cell secretome. J Clin Med 2013 Dec;2(4):302-327.

61. Kumar A, Kumar V, Rattan V, Jha V, Bhattacharyya S. Secretome cues modulate the neurogenic potential of bone marrow and dental stem cells. Mol Neurobiol 2017 Aug;54(6):4672-4682.

62. Parekkadan B, van Poll D, Suganuma K, Carter EA, Berthiaume F, Tilles AW, Yarmush ML. Mesenchymal stem cellderived molecules reverse fulminant hepatic failure. PLoS One 2007 Sep;2(9):e941.

63. Timmers L, LimSK, Hoefer IE,ArslanF, Lai RC, van OorschotAA, Goumans MJ, Strijder C, Sze SK, Choo A, et al. Human mesenchymal stem cell-conditioned medium improves cardiac function following myocardial infarction. Stem Cell Res 2011 May;6(3):206-214.

64. Chang $\mathrm{CP}$, Chio CC, Cheong CU, Chao CM, Cheng BC, Lin MT. Hypoxic preconditioning enhances the therapeutic potential of the secretome from cultured human mesenchymal stem cells in experimental traumatic brain injury. Clin Sci (Lond) 2013 Feb;124(3):165-176.

65. Teixeira FG, Carvalho MM, Panchalingam KM, Rodrigues AJ, Mendes-Pinheiro B, Anjo S, Manadas B, Behie LA, Sousa N, Salgado AJ. Impact of the secretome of human mesenchymal stem cells on brain structure and animal behavior in a rat model of Parkinson's disease. Stem Cells Transl Med 2017 Fev;6(2):634-646.

66. He J, Wang Y, Sun S, Yu M, Wang C, Pei X, Zhu B, Wu J, Zhao $\mathrm{W}$. Bone marrow stem cells-derived microvesicles protect against renal injury in the mouse remnant kidney model. Nephrology (Carlton) 2012 Jul;17(5):493-500.

67. Brini AT, Amodeo G, Ferreira LM, Milani A, Niada S, Moschetti G, Franchi S, Borsani E, Rodella LF, Panerai AE, et al. Therapeutic effect of human adipose-derived stem cells and their secretome in experimental diabetic pain. Sci Rep 2017 Aug;7(1):9904.

68. Soundara Rajan T, Giacoppo S, Diomede F, Bramanti P, Trubiani O, Mazzon E. Human periodontal ligament stem cells secretome from multiple sclerosis patients suppresses NALP3 inflammasome activation in experimental autoimmune encephalomyelitis. Int J Immunopathol Pharmacol 2017 Sep;30(3):238-252. 
69. Hofer HR, Tuan RS. Secreted trophic factors of mesenchymal stem cells support neurovascular and musculoskeletal therapies. Stem Cell Res Ther 2016 Sep;7(1):131.

70. Kim MJ, Kim ZH, Kim SM, Choi YS. Conditioned medium derived from umbilical cord mesenchymal stem cells regenerates atrophied muscles. Tissue Cell 2016 Oct;48(5):533-543.

71. Mellows B, Mitchell R, Antonioli M, Kretz O, Chambers D, Zeuner MT, Denecke B, Musante L, Ramachandra DL, DebacqChainiaux F, et al. Protein and molecular characterization of a clinically compliant amniotic fluid stem cell-derived extracellular vesicle fraction capable of accelerating muscle regeneration through enhancement of angiogenesis. Stem Cells Dev 2017 Sep;26(18):1316-1333.

72. Sevivas N, Teixeira FG, Portugal R, Araújo L, Carriço LF, Ferreira N, Vieira da Silva M, Espregueira-Mendes J, Anjo S, Manadas B, et al. Mesenchymal stem cell secretome: a potential tool for the prevention of muscle degenerative changes associated with chronic rotator cuff tears. Am J Sports Med 2016 Aug;45(1):179-188.

73. Nakamura $Y$, Miyaki S, Ishitobi H, Matsuyama S, Nakasa T, Kamei N, Akimoto T, Higashi Y, Ochi M. Mesenchymal-stemcell-derived exosomes accelerate skeletal muscle regeneration. FEBS Lett 2015 May;589(11):1257-1265.

74. Yeng CH, Chen PJ, Chang HK, Lo WY, Wu CC, Chang CY, Chou $\mathrm{CH}$, Chen $\mathrm{SH}$. Attenuating spinal cord injury by conditioned medium from human umbilical cord blood-derived CD34+ cells in rats. Taiwan J Obstet Gynecol 2016 Feb;55(1):85-93.

75. Wang Y, Yu D, Liu Z, Zhou F, Dai J, Wu B, Zhou J, Heng BC, Zou $\mathrm{XH}$, Ouyang $\mathrm{H}$, et al. Exosomes from embryonic mesenchymal stem cells alleviate osteoarthritis through balancing synthesis and degradation of cartilage extracellular matrix. Stem Cell Res Ther 2017 Aug;8(1):189.

76. Platas J, Guillén MI, del Caz MDP, Gomar F, Castejón MA, Mirabet V, Alcaraz MJ. Paracrine effects of human adiposederived mesenchymal stem cells in inflammatory stressinduced senescence features of osteoarthritic chondrocytes. Aging (Albany NY) 2016 Aug;8(8):1703-1717.

77. IshikawaJ,TakahashiN,Matsumoto T, Yoshioka Y, YamamotoN, Nishikawa M, Hibi H, Ishigro N, Ueda M, Furukawa K, et al. Factors secreted from dental pulp stem cells show multifaceted benefits for treating experimental rheumatoid arthritis. Bone 2016 Feb;83:210-219.
78. Platas J, Guillén MI, del Caz MDP, Gomar F, Mirabet V, Alcaraz MJ. Conditioned media from adipose-tissue-derived mesenchymal stem cells downregulate degradative mediators induced by interleukin-1 $\beta$ in osteoarthritic chondrocytes. Mediators Inflamm 2013 Dec;2013:357014.

79. Hu J, Deng G, Tian Y, Pu Y, Cao P, Yuan W. An in vitro investigation into the role of bone marrow-derived mesenchymal stem cells in the control of disc degeneration. Mol Med Rep 2015 Oct;12(4):5701-5708.

80. Cheng X, Zhang G, Zhang L, Hu Y, Zhang K, Sun X, Zhao C, $\mathrm{Li} \mathrm{H}$, Li YM, Zhao J. Mesenchymal stem cells deliver exogenous miR-21 via exosomes to inhibit nucleus pulposus cell apoptosis and reduce intervertebral disc degeneration. J Cell Mol Med 2018 Jan;22(1):261-276.

81. Tavakoli Dargani Z, Singla R, Johnson T, Kukreja RC, Singla DK. Exosomes derived from embryonic stem cells inhibit doxorubicin and inflammation induced pyroptosis in muscle cells. Can J Physiol Pharmacol 2017 Sep;1-4. Epub ahead of print.

82. Ogata K, Katagiri W, Osugi M, Kawai T, Sugimura Y, Hibi H, Nakamura S, Ueda M. Evaluation of the therapeutic effects of conditioned media from mesenchymal stem cells in a rat bisphosphonate-related osteonecrosis of the jaw-like model. Bone 2015 May;74:95-105.

83. Katagiri W, Osugi M, Kawai T, Hibi H. First-in-human study and clinical case reports of the alveolar bone regeneration with the secretome from human mesenchymal stem cells. Head Face Med 2016 Jan;12(1):5.

84. Lee K, Kim H, Kim JM, Kim JR, Kim KJ, Kim YJ, Park SI, Jeong JH, Moon YM, Lim HS, et al. Systemic transplantation of human adipose-derived stem cells stimulates bone repair by promoting osteoblast and osteoclast function. J Cell Mol Med 2011 Oct;15(10):2082-2094.

85. Osugi M, Katagiri W, Yoshimi R, Inukai T, Hibi H, Ueda M. Conditioned media from mesenchymal stem cells enhanced bone regeneration in rat calvarial bone defects. Tissue Eng Part A 2012 Jul;18(13-14):1479-1489.

86. Ando Y, Matsubara K, Ishikawa J, Fujio M, Shohara R, Hibi H, Ueda M, Yamamoto A. Stem cell-conditioned medium accelerates distraction osteogenesis through multiple regenerative mechanisms. Bone 2014 Apr;61:82-90.

87. Hamrick MW. The skeletal muscle secretome: an emerging player in muscle-bone crosstalk. Bonekey Rep 2012 Apr;1:60. 